\title{
The impact of organizational characteristics on the outcomes of septic patients admitted to the ICU
}

\author{
L Sarmet Cunha Farah Rabello ${ }^{1,2^{*}}$, F Bozza ${ }^{2}$, J Kahn ${ }^{3}$, P Brasil ${ }^{2}$, D Angus ${ }^{3}$, J Salluh², M Soares², \\ ORCHESTRA Study Investigators
}

From ESICM LIVES 2015

Berlin, Germany. 3-7 October 2015

\section{Introduction}

Critically ill septic patients have high rates of death, complications and resource use, mainly in emerging countries.

\section{Objectives}

To investigate the impact of organizational factors on the outcomes of septic patients in a large sample of Brazilian ICUs.

\section{Methods}

Retrospective cohort study in 6,779 patients with severe sepsis $(\mathrm{n}=5,294,78 \%)$ or septic shock $(\mathrm{n}=1,485,22 \%)$ directly admitted from the emergency department to 69 ICUs (private hospitals, $\mathrm{n}=62(90 \%)$; medical-surgical; $\mathrm{n}=$ 57(83\%)) during 2013. We retrieved demographic, clinical and outcome data from an electronic ICU quality registry (Epimed Monitor System). We surveyed ICUs using a standardized questionnaire regarding organizational aspects, staffing patterns and process of care. We used multilevel logistic regression analysis to identify factors associated with hospital mortality.

\section{Results}

38 (55\%) ICUs had critical care training programs. Median graduate nurse-bed ratio was 0.23 (IQR, 0.18-0.29) and board-certified intensivists were present $24 / 7$ in $16(23 \%)$ of ICUs. Routine clinical rounds occurred in $59(86 \%)$ and daily checklists were used in $34(49 \%)$ ICUs. Sepsis protocol was implemented in $83 \%$ ICUs. The most frequent sources of infection were pulmonary

${ }^{1}$ Instituto Nacional de Cancer, Rio de Janeiro, Brazi

Full list of author information is available at the end of the article
$(3,536(52 \%))$ and urinary tract (1,283 (19\%)). Invasive mechanical ventilation was used in $1,373(20 \%)$ patients and dialysis in 289 (4\%) patients. SAPS 3 score was 54 (47-62) points. ICU and hospital mortality rates were $19 \%$ and 26\%. Adjusting for relevant patients' characteristics (SAPS 3 score, admission diagnosis, chronic health status, comorbidities, MV use), case-volume and type of ICU, average graduate nurse/bed ratio during shifts $(\mathrm{OR}=0.254(95 \% \mathrm{CI}, 0.068-0.945))$ and the number of other implemented protocols $(\mathrm{OR}=0.932(0.862-1.008))$ were associated with lower mortality. In a second model, the presence of intensivist nurses $24 / 7$ in the ICU $(\mathrm{OR}=0.600(0.390-0.924))$ was also associated with better outcomes.

\section{Conclusions}

Nurse staff patterns and the implementation of clinical protocols were associated with mortality in septic patients and are potential targets to improve care of these patients in emerging countries.

\section{Authors' details}

Instituto Nacional de Cancer, Rio de Janeiro, Brazil. ${ }^{2} D^{\prime}$ Or Institute for Research and Education, Rio de Janeiro, Brazil. ${ }^{3}$ University of Pittsburgh Medical Center, Pittsburgh, PA, USA.

Published: 1 October 2015

doi:10.1186/2197-425X-3-S1-A473

Cite this article as: Sarmet Cunha Farah Rabello et al: The impact of organizational characteristics on the outcomes of septic patients admitted to the ICU. Intensive Care Medicine Experimental 2015 3(Suppl 1): A473.

\section{SpringerOpen ${ }^{\circ}$}

(c) 2015 Sarmet Cunha Farah Rabello et al.; This is an Open Access article distributed under the terms of the Creative Commons Attribution License (http://creativecommons.org/licenses/by/4.0), which permits unrestricted use, distribution, and reproduction in any medium, provided the original work is properly cited. 